\title{
JICOTÉNCAL, LOS DISFRACES DE LA HISTORIA
}

FRANCISCO JOSÉ LÓPEZ ALFONSO

Hay en el tiempo un interregno enteramente determinado por cosas que ya no existen y por cosas que todavía no existen. Es algo así como una brecha en el tiempo cuya lucha constante frente al pasado y al futuro le otorga existencia. La brecha no es un simple intervalo, sino un paralelogramo de fuerzas. Es posible que cualquier presente histórico pueda ser considerado así, pero esta condición adquiere una contundencia extraordinaria en las revoluciones, esos intensos momentos en los que un modelo de sociedad se va destruyendo a la vez que se construye otro radicalmente distinto. La violencia de ese huracán generador es tal que si sus mismos partidarios la temen, conscientes de lo poco que controlan los acontecimientos, sus detractores no pueden evitar sentirse fascinados: «QQué espectáculo, qué actores!», escribía Edmund Burke a lord Charlemont, refiriéndose a la Revolución francesa.

Aunque menos prestigiosa que ésta y la Revolución americana, a las que toma por modelos ideológicos en sus manifestaciones teóricas, la Emancipación hispanoamericana pertenece de igual modo a ese proceso de liquidación del Antiguo Régimen, pues España representaba no sólo la antigua opresión metropolitana, sino también el viejo modelo social. Como «un mundo coherente, un verdadero mundo de ideas» caracteriza José Luis Romero a ese viejo mundo hispánico de la península y de las colonias, cuyo marco era «la concepción católica de la Contrarreforma y la concepción política de la monarquía absoluta tal como la entendían los Austria. Estrictas ambas e intolerantes, contribuían a conformar una imagen autoritaria tanto de la vida social y política como de la vida del pensamiento»" ${ }^{\text {. La }}$ Emancipación significaba así el tránsito de una sociedad de fundamentos sacros, una teocracia, a una sociedad profana, la sociedad civil. Importa destacar este aserto, pues constituye una constante la paradójica importancia atribuida al catolicismo y sus ministros en la formación de un pensamiento que preparase la independencia e incluso la consumara. Desde el surgimiento de un sentido crítico promovido por los jesuitas expulsos, pasando por la bélica actividad de los curas Hidalgo y Morelos, hasta la generalizada declaración como religión oficial en los nuevos estados, a veces con la expresa prohibición de cualquier otra, la presencia del catolicismo resultaba tan abrumadora como incuestionable la vigencia rectora de los principios ilustrados en el proceso emancipador. La ilustración en el mundo hispano tuvo que ser, pues, sinceramente ortodoxa y su impiedad un mito elaborado por el joven Menéndez y Pelayo. De hecho, se admite la existencia de una «ilustración católica» o «catolicismo ilustrado». «Se trata -dice Cedomil Goic- de un iluminismo que propagando la verdad y la razón y combatiendo las creencias supersticiosas, los vicios y las inepcias sociales, conserva los valores de la fe cristiana $y$ se muestra, en todos sus extremos, creyente; y que hace compatible el combate de los errores y de la ignorancia, y el castigo de las limitaciones de la sociedad, con la fe cristiana»².

Razón y fe. El compromiso, sin embargo, resulta complejo; aunque se insista en diferenciar la penetración de las ideas políticas francesas, a través de la experiencia de las revolu-
José Luis Romero, «Prólogo», en Romero, José Luis y Romero, Luis Alberto (sel.), Pensamiento polifico de la Emancipación (179018251, vol. 1, Caracas, Biblioteca Ayacucho, 1977, págs. ix-xlv, pág. xvi.

2

Cedomil Goic, Historia de la novela hispanoamericana, Valparaíso, Ediciones Universitarias de Valparaíso, 1972, pág. 22.
Jiconténcal, los disfraces

de la historia

FRANCISCO JOSE LOPEZ ALFONSO 


\section{JICOTENCAI.}

TOMO PRIMIERO

FILADELFIA :

IMPRENTA DE GULLERMO STAVELS 1826.

3

José Luis Romero, «Prólogo», op cit., pág. xxvi.

4

Karl Marx, «Los límites de la emancipación política», en Antología, Barcelona, Ediciones $\mathrm{Pe}$ nínsula, (págs. 66-73), pág. 66.

5

Ibidem, pág. 71.

6

Camilo Henríquez, "De la influencia de los escritos luminosos sobre la suerte de la humanidad", en Fenández, Teodosio (sel.), Teoría y crítica literaria de la Emancipación hispanoamericana, Alicante, Generalitat Valenciana/Instituto de Cultura Juan Gil-Albert, 1997, (págs. 45-47), pág. 46.

\section{7}

Teodosio Fernández, «Introducción", Teoría y crítica literaria ..., op. cit., (págs. 11-40), pág. 17.

8

Camilo Henríquez, «De la influencia de los escritos luminosos sobre la suerte de la humanidad», en Fenández, Teodosio (sel.), Teoría y crítica literaria de la Emancipación hispanoamericana, op. cit., (págs. 45-47), pág. 46.

Jiconténcal, los disfraces de la historia

FRANCISCO JOSÉ LÓPEZ ALFONSO ciones de Francia y d los Estados Unidos, y la de otras ideas, en especial, las religiosas y las culturales, a través de la cautelosa elaboración realizada por los ilustrados españoles ${ }^{3}$. La importancia decisiva que la política adquiría en la nueva sociedad era incompatible con una comprensión estrictamente cristiana de lo secular. En la sociedad burguesa, el ciudadano era lo opuesto al súbdito del Antiguo Régimen, obediente a la Iglesia, a los príncipes y a las corporaciones. La reivindicación de autonomía de este sujeto, cuya libertad terminaba conformándose con la razón, tenía como objetivo librar a la individualidad del peso de la institución religiosa. Era la misma liberación que había experimentado el pensamiento filosófico secular al escapar de la sumisión impuesta por la Iglesia en la Edad Media, «philosophia ancilla theologiae est», y que Kant definió en su escrito ¿Qué es ilustración? (1784): «La Ilustración es la salida del hombre de su autoculpable minoría de edad. La minoría de edad significa la incapacidad de servirse de su propio entendimiento sin la guía de otro. Uno mismo es culpable de esta minoría de edad cuando la causa de ella no reside en la carencia de entendimiento, sino en la falta de decisión y valor para servirse por sí mismo de él sin la guía de otro».

Es más, el estado moderno, el estado político, únicamente podía acceder a la existencia distinguiéndose de la forma de la autoridad y de la fe, como advirtió Hegel en su Filosofía del Derecho y ratificó Marx: «El Estado en su forma propia y característica, en cuanto Esta$d o$, se emancipa de la religión emancipándose de la religión oficial, o sea reconociéndose a sí mismo como Estado y no a una religión» ${ }^{4}$. Es decir, es la consideración del hombre a nivel de especie, y no la de Dios, su fundamento. Por otro lado, ello resultaba independiente de que muchos o incluso la mayoría continuara siendo religiosa, pues se trataba de una cuestión privada. La religión dejaba de ser la esencia de la comunidad para convertirse en la esencia de la diferencia. Ahora no era más que la confesión de una extravagancia personal, a la que el astillamiento sin límites, por ejemplo en Norteamérica, le daba incluso de manera externa una apariencia puramente individual. Una cuestión distinta es que una vez realiza- do el brutal parto del estado político, como tal, la sociedad burguesa, su presupuesto realmente existente, detuviera el proceso revolucionario para garantizar su conservación. «Por eso el drama político acaba en la restauración de la religión, de la propiedad privada, de todos los elementos de la sociedad burguesa, tan necesariamente como la guerra termina en la paz» ${ }^{5}$. Entonces, el «catolicismo ilustrado», antes de la Emancipación, es un esfuerzo desesperado de la religión por evitar la secularización, por controlar los profundos e inevitables cambios. Después de la Emancipación, la «ilustración católica» es apenas un instrumento de control del nuevo poder, una apariencia de religión.

Si quería alcanzarse el auténtico objetivo de la Emancipación, la educación moral no podía dejarse en manos del clero. Era necesario crear nuevas instituciones que se ocuparan de la pedagogía social o al menos transformar radicalmente las existentes. El chileno Camilo Henríquez, un fraile, señalaba en 1812 la ineludible obligación de desarrollar una instrucción pública que rompiese con el método escolástico y su enseñanza en latín, con los atrasados planes de estudio en las escuelas: «La ilustración debe hacerse popular, pero las instituciones antiguas fueron contrarias a la difusión de las luces» ${ }^{6}$. Y depositaba su confianza, como ha destacado Teodosio Fernán$\mathrm{dez}^{7}$, en la capacidad de la literatura como primer paso en la educación de los pueblos: «Es también cierto que la educación se adelanta y se desenvuelve en los pueblos con lentitud, que las letras tienen su infancia, que las facultades de imaginación se perfeccionan antes que las del pensamiento, observación y cálculo, y que la sana política y la buena legislación son el último resultado de nuestras reflexiones. Feliz el pueblo que tiene poetas, a los poetas seguirán filósofos, a los filósofos, los políticos profundos» ${ }^{8}$.

Esta literatura, como exigía la labor pedagógica asignada y confirman los testimonios conservados -las poesías de Bello, las novelas de Fernández de Lizardi, los diálogos gauchescos, por mencionar los más significativos-, debía de ser un discurso claro, bien informado, que presentase todas las apariencias de la coherencia y cuyo efecto consistiese en legitimar y hacer amable la ideología de que era portadora. Encargada de la educación sentimental y ética de la burguesía y posterior- 
mente de la sociedad civil, la literatura exaltaba la espiritualidad, la «mejor parte del hombre» y rehabilitaba las «facultades superiores del desear»: el amor a la justicia, a la patria, a la familia, al trabajo. La ideología moral producida a través de la literatura y de otras instituciones solidarias en sus objetivos, como la prensa, la instrucción pública o el derecho, constituyen el eje y el «aroma espiritual» del estado-nación en su origen y fortalecimiento.

Atrás quedaba la «cultura intelectual y artística» de la colonia que, como apuntó Pedro Henríquez Ureña en sus Corrientes literarias..., «suponía la coronación de la vida social, del mismo modo que la santidad era la coronación de la vida individual»?, sugiriendo con la comparación una compleja red de vínculos entre religión, sociedad y cultura artística que explica los contenidos socio-religiosos de las obras nacidas en y para esa sociedad y el carácter predominantemente religioso de los elementos de la vida literaria ${ }^{10}$. Ahora, en las primeras décadas del siglo XIX, el clérigo escritor iba siendo sustituido por el laico y la literatura cambiaba de función: «tenía una utilidad política (...) La literatura demostró su utilidad para la vida pública durante las guerras de independencia. Con frecuencia tomó forma de periodismo u oratoria, o de ensayo político; ya hemos visto que también tomó forma de novela (nuestra primera novela, $E l$ Periquillo Sarniento perseguía un asunto social); otras veces era el drama patriótico, la oda clásica que se leía en público, el himno que se ponía en música» ${ }^{11}$. Pero esta labor no se limitó a los años de la independencia política, porque el objeto, insisto, no era simplemente romper con España sino acabar con el Antiguo Régimen. Y ésta era una guerra mucho más larga y difícil: «Durante los cincuenta agitados que transcurren entre 1820 y 1870 , emprendiose una tarea titánica. Se cambió la estructura de la sociedad»12. De ahí que el romántico Sarmiento se esforzara con el mismo ahínco que los ilustrados Fernández de Lizardi y Bello en crear una opinión pública y mejorar la educación escolar. La función cívica del escritor no había cambiado.

La tarea se cumplía en un marco de lectura radicalmente antagónico al existente durante el periodo colonial y al que fue sustituyendo de modo progresivo. La lectura «intensiva», esto es, la lectura repetitiva a lo largo de toda la vida de un reducido canon de textos, en su mayor parte de índole religiosa, fue sustituido por una lectura «extensiva», es decir, ávida de materiales nuevos y diversos, que manifestaba un modo moderno y laico de leer, práctico, del que no estaba exento el ánimo de entretenerse y aún de obtener placer $^{13}$. Las pautas de recepción, marcadamente autoritarias, fueron sustituidas por una lectura comprensiva, racional; todo un acto de liberación frente al sojuzgamiento espiritual del Antiguo Régimen.

En el ámbito estrictamente literario las marcas autoritarias de la lectura fueron sustituidas por el factor emocional. Esta lectura sentimental, es decir, de empatía entre el lector y el sujeto lírico y, de manera especial, entre el lector y los personajes explica la enorme capacidad de penetración de la literatura, su enorme eficacia durante cierto periodo, frente a las resistencias que inevitablemente encontraba la religión, con la que ahora competía por el control de las conciencias. En este sentido puede entenderse la decisión de Fernández de Lizardi de escribir y publicar El Periquillo Sarniento y no como un simple azar empujado por las crecientes dificultades que la censura ponía a su actividad crítica en la prensa. Más bien, es creíble que Lizardi optase por el género novelesco al considerarlo más eficaz que la exhortación directa para la reforma de de la sociedad ${ }^{14}$. Así lo sugieren estas palabras de Pedro Sarmiento a sus hijos, destinatarios internos del relato: «(...) y quisiera que la lectura de mi vida os fuera provechosa y entretenida, y bebierais el saludable amargo de la verdad en la dorada copa del chiste y de la erudición. Entonces sí que estaría contento y habría cumplido cabalmente con los deberes de un sólido escritor, según Horacio, y conforme mi libre traducción: De escritor el oficio desempeña/quien divierte al lector y quien lo enseña» ${ }^{15}$.

Dulce, pero sobre todo utile. No sin motivo, el ecuatoriano Francisco J. E. de Santa Cruz y Espejo había declarado ya en 1799, en El Nuevo Luciano de Quito a «la novela como instrumento moral más adecuado que la propia historia» ${ }^{16}$. José María Heredia, tres décadas después, confirmaba cómo en Europa «crecía el influjo de las novelas» convirtiéndose en «la lectura favorita de todas las clases de
9

Pedro Henríquez Ureña, Las corrientes literarias en la América Hispánica, México, F.C.E., 1949, págs. 45-46.

10

Vid. Rafael Gutiérrez Girardot, «La historiografía de Pedro Henríquez Ureña: promesa y desafio», en Aproximaciones, Bogotá, Procultura, 1986, pág. 78.

11

Pedro Henríquez Ureña, Las corrientes literarias..., op. cit., pág. 118.

12 Ibidem, pág. 116.

13

Obsérvese que esta novedosa forma de leer se corresponde con precisión al carácter de la revista.

14

Vid. Jean Franco, "La heterogeneidad peligrosa: Escritura y control social en vísperas de la independencia mexicana, Hispamérica, 1983, núm. 34/35, (págs. 3-34), pág. 18.

15

José Joaquín Fernández de Lizardi, El Periquillo Sarniento (1816) México, Porrúa, 1978, pág. 41.

16

Citado por Luiz Costa Lima, $O$ fingidor e o censor no ancien régime, no lluminismo e Hoje, Rio de Janeiro, Forense-Universitaria, 1988, pág. 243.

Jiconténcal, los disfraces de la historia

FRANCISCO JOSÉ LOPEZ ALFONSO 


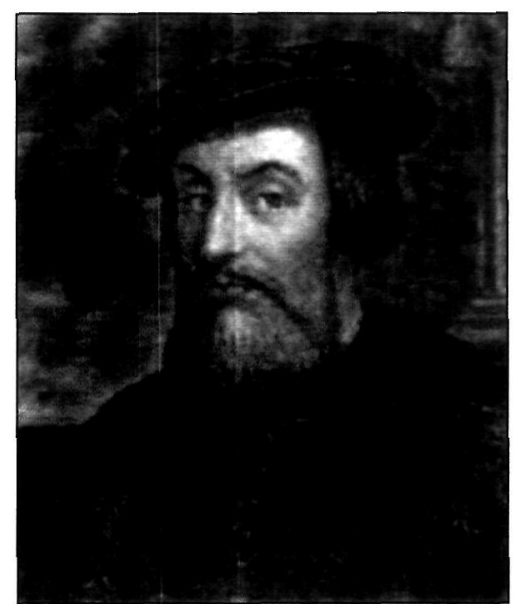

Hernán Cortés.

17

José María Heredia, «Ensayo sobre la novela», en Fenández, Teodosio (sel.), Teoría y crítica literaria de la Emancipación hispanoamericana, op. cit., (págs. 113-120), pág. 116.

18

Alejandro González Acosta, autor del libro El enigma de Jicoténcal, México, UNAM/Instituto Tlaxcalteca de Cultura, 1997, señala al poeta cubano José María Heredia como el autor más probable de la novela. Debo esta información a Margo Glantz y la lectura del ensayo de González Acosta a Beatriz Aracil. A ambas, mi agradecimiento.

19

Jicoténcal, Filadelfia, Imprenta de Guillermo Stavely, 1826. Los números entre paréntesis al final de las citas corresponden al tomo y página de esta edición. la sociedad $\gg^{17}$. El fenómeno, que a buen seguro, se repitió en Hispanoamérica, permite comprender la esperanza y hasta la convicción con que fue concebida Jicoténcal.

Esta novela, sin indicación de autor $^{18}$, fue publicada en 1826 , en Filadelfia, en la imprenta de Guillermo Stavely y tiene tal vez el mérito de mostrar con gran claridad la ideología que animó a cierta corriente independentista que tuvo en el Rousseau del Contrato social a su teórico y en la república jacobina, su modelo. La novedad consistía en que para ilustrar esta ideología el autor selecciona un hecho histórico distante en el tiempo, la conquista de México y que, en su narración, se apoya explícitamente en la obra de un historiador pretérito. En el primero de los seis libros que integran la novela, se lee esta curiosa nota a pie de página: «Todo lo que en el discurso de esta obra irá escrito con letra cursiva, será copiado literalmente de la Historia de la conquista de México por don Antonio Solís, que es el escritor más entusiasta de las prendas y méritos de Hernán Cortés» ${ }^{19}$ (Tomo I, pág. 14).

Esta precisión relativa a la parcialidad de Solís por Cortés tiene por objeto destacar cómo, a pesar de este entusiasmo, la figura del conquistador resulta condenada de manera inapelable por los mismos hechos, al margen de la objetividad del autor-narrador, implícita en la declaración de «literaliedad». Pero, por otro lado, resultaría una estulticia el mantener un acatamiento servil a la autoridad de la fuente:

"(...) el ojo perspicaz del filósofo sabe distinguir entre el fango y basura que ensucian el papel de las historias, algunas chispas de verdad, que no han podido apagar ni el fanatismo ni la servil adulación. Estas chispas lo conducen; y cuando llega su día, desentierra los hechos, y los presenta al mundo: y si no le es posible exhumarlos de sus antiguos sepulcros en toda su integridad, a lo menos no los tuerce ni los afea con preocupaciones y con bajezas» (Tomo II, págs. 168169).

Este trabajo de recuperación de la verdad histórica por parte del autor-narrador, del filósofo, como se considera a sí mismo es antes un enaltecimiento del actuar que una afirmación de la actitud básicamente contemplativa del historiador y de la conciencia filosófica en general. Con otras palabras, la pregunta qué debo hacer es más importante para el autor anónimo que las cuestiones qué puedo saber y qué puedo esperar y las reflexiones de este filósofo, un auténtico propagandista a pesar de su supuesta objetividad, son una apelación directa a la responsabilidad del lector para que evite cualquier situación análoga a la narrada en Jicoténcal; más claramente, el autor pretende convencer al lector hispanoamericano de la necesidad de luchar unidos por la emancipación de América:

¡Pueblos! Si amáis vuestra libertad, reunid vuestros intereses y vuestras fuerzas y aprended de una vez que si no hay poder que se estrelle cuando choca contra la inmensa fuerza de vuestra unión, tampoco hay enemigo tan débil que no os venza y esclavice cuando os falta aquella. Tlaxcala es un ejemplo palpable de esta verdad. (...) (Tomo II, págs. 5-6)

(...) cuando el despotismo descarga así su mano de hierro a presencia de un pueblo que no le ahoga o despedaza en la justa indignación que debe excitar tan bárbara tiranía, ese pueblo sufre justamente sus cadenas, y aún éstas son poco para lo que merece su cobarde y vil paciencia. (Tomo II, págs. 167-168)

La simple lectura de estos fragmentos permite deducir que los hechos narrados en Jicoténcal no son sino el ejemplo alusivo a los acontecimientos coetáneos al autor de la novela; dicho con palabras del anónimo autor, aunque alterando su sentido: con el episodio de Tlascala «le parece al lector que se le habla de otro siglo y de otro pueblo» (Tomo I, pág. 155).

Por otro lado, estas citas condensan la ideología revolucionaria que la narración desarrolla pedagógicamente con claridad de teorema. El pueblo, principio que permite dar cuenta del estado moderno, es aquí la república de Tlascala, representada por su general Jicoténcal, el joven, que se enfrenta, hasta perder la vida, al conquistador español, al tirano Cortés. La ideología del pueblo es, entonces, la ideología de la resistencia -resistencia al tirano, resistencia al monarca, resistencia al Antiguo Régimen-, y la revolución, simplemente el reinicio del modelo estatal. Se trata de reconstituir la soberanía confiscada por el tirano.

Al respecto es significativo el contraste entre dos episodios muy parecidos. En el prime- 
ro, Teutila, la amada y esposa de Jicoténcal, descubre a un español fuertemente atado en una cueva. Un anciano tlascateca le explica que el español ha violado a una mujer que, al perder el honor, también ha perdido la vida y que él y sus dos hijos resolvieron que el español debía morir. Teutila les reprocha esa conducta que pervierte el orden social y les recuerda que mientras existan autoridades judiciales, por más corruptas que sean, es necesario respetarlas; «lo demás -dice- es una confusión y una anarquía» (Tomo II, págs. 178-179).

En el segundo es la propia Teutila quien intenta asesinar a Cortés, para vengar la muerte de su esposo Jicoténcal. Y sin embargo, no hay incongruencia, porque, por encima de la venganza personal, el tiranicidio significaría recobrar el imperio de la ley, anulada a la voluntad e interés del tirano; mientras que la decisión de los tres tlascaltecas sería una manifestación más de la ausencia de la ley.

Esta cuestión ya había sido el tema de un diálogo entre Jicoténcal y su amigo Diego de Ordaz, un soldado español de corazón recto. Contra la defensa de la monarquía levantada por Ordaz, Jicoténcal argumenta lo siguiente: «El poder de uno solo no me parece soportable», porque "cuando el poder de uno solo domina, no hay más leyes que su voluntad». Por el contrario, en el «gobierno popular», «las leyes» son «el orden y arreglo de lo que exige la utilidad común» (Tomo I, págs. 160161 y 162$)$.

De modo que el advenimiento revolucionario del pueblo soberano inaugura el reino del derecho y de la ley. Cuando el pueblo soberano accede a la soberanía es el derecho el que accede al poder. La revolución, de hecho, no es más que el contrato social. La república corresponde al advenimiento de la ley común a todos; una ley, que secuestrada por Cortés, Jicoténcal y Teutile, tío de Teutila, se comprometen a darse, una vez derrotado el tirano, firmando una paz duradera entre sus dos estados, Tlascala y México, siempre enemigos. La revolución o contrato social, la Emancipación, puede interpretarse entonces como una superación del estado de naturaleza, en el que el hombre ya era libre, pero en el que tenía que luchar permanentemente para conservar su libertad. La revolución sería la confirmación de esta libertad como pasaje de la fuerza a la ley o, lo que es lo mismo, de la soledad a la vida en común.
Ésta es básicamente la ideología que la novela expone en las reflexiones y en los diálogos y que ilustra la narración. Para hacerlo al anónimo autor le hubiese bastado ceñirse a la Historia de Solís, a la que por otra parte sigue muy de cerca en el vaivén de los acontecimientos; pero, como ninguna ideología está hecha sólo de argumentos lógicos, a la narración político-militar añade una segunda intriga amorosa absolutamente ficticia, como versión emocional de la primera: los amores de la hermosa india Teutila -alegoría de América y único personaje no histórico- y el valeroso Jicoténcal, obstaculizados por los inmorales deseos de Cortés y, finalmente, destruidos por su ambición. Los triángulos amorosos, en los que participan Diego de Ordaz, enamorado de Teutila, doña Marina, la Malinche, amante de Cortés, enamorada de Diego de Ordaz y por un tiempo objeto de deseo de Jicoténcal, dan a esta intriga un carácter marcadamente teatral, con las entradas y salidas de amantes celosos y furibundos, con sus discursos altisonantes y sus duelos de capa y espada, sus suspiros y bufidos de despecho y, sobre todo, con su trágico final en el que Jicoténcal y Teutila mueren víctimas de la tiranía. El objeto de esta intriga amorosa no es otro que el de conmover los ánimos del público lector, dado que las verdades del sentimiento, según Diderot, se graban en el alma más profundamente que las que se basan en la argumentación del mayor rigor lógico; conmover los ánimos para promover el entusiasmo revolucionario, como reclamaba Camilo Henríquez de la tragedia:

Ahora es cuando debe llenar la escena la sublime majestad de Melpémone, respirar nobles sentimientos, inspirar odio a la tiranía y desplegar toda la dignidad republicana. ¡Cuándo más varonil ni más grandiosa que penetrándose de la justicia de nuestra causa, y de los derechos sacratísimos de los pueblos! ¡Cuándo más interesante que enterneciendo con la memoria de nuestras antiguas calamidades! ¡Ah!, entonces no serán estériles las lágrimas; su fruto será el odio de la tiranía, y la execración de los tiranos ${ }^{20}$.

Es interesante notar que en su desarrollo ideológico la novela afirma exclusivamente los fundamentos humanos, combatiendo con insistencia las pretensiones de la religión. Nada menos que en cuatro ocasiones quiere el autor que los personajes polemicen con fray Bartolomé Olmedo a propósito de la religión, re-

\section{0}

Camilo Henríquez, «Del entusiasmo revolucionario", en Fenández, Teodosio (sel.), Teoría y crítica literaria de la Emancipación hispanoamericana, op. cit., (págs. 49-52), pág. 52. Quizá hoy resulte difícil creer en la eficacia de la literatura, pero en aquel momento de entusiasmo juvenil, llevado al extremo por las fuerzas de las circunstancias, el proyecto político no solo representaba una esperanza, sino una convicción; de modo que la literatura, haciéndose eco de estas creencias, todavía representaba la exigencia suprema del espiritu.
Jiconténcal, los disfraces

de la historia

FRANCISCO JOSÉ LÓPEZ ALFONSO 

rio de Luis Bonaparte, en El Manifiesto comunista y otros ensayos, Madrid, Sarpe, 1983, págs. 103-210, pag. 107. sultando siempre derrotado éste en su defensa del catolicismo. Hay una quinta ocasión en la que discute con doña Marina, pero aquí no se trata propiamente de una polémica sino de mostrar las malas consecuencias de una educación religiosa superficial. Con todo, ni Dios ni la religión son negados. Teutila, Jicoténcal, el joven, y su padre, Jicoténcal, el anciano, los polemistas indígenas de fray Bartolomé con sus «luces claras» entienden que Dios existe y que es el ordenador del mundo, pero se niegan a admitir aquellos misterios que la razón no puede comprender. En realidad, la existencia de este Dios admisible es puramente fantasmal. Este Dios tolerado por la razón nada tiene ver con el auténtico Dios, todopoderoso e incomprensible para el entendimiento. Lo que había sucedido, como muy bien supo interpretar Bernhard Groethuysen, es que el Dios cristiano había cambiado a lo largo del siglo XVIII sin que muchos cristianos se apercibieran de ello. Dios había sido secularizado y reducido a categorías comprensibles, un Dios justiciero que al final de los días premiaba a los bueno y castigaba a los malos, siempre según patrones humanos de justicia, Éste es el «supremo juez» tantas veces invocado en la novela, el «Dios vengado» al que se reserva para sí el golpe terrible con el que será castigado Cortés, según la moribunda Teutila, el mismo que se manifiesta en la agonía terrible de Magiscatzin, el senador traidor de Tlascala.

El rechazo del incomprensible Dios cristiano es, además, consecuente con el rechazo del Antiguo Régimen, porque en la arbitrariedad de su poder se vislumbra el origen y el modelo de la arbitrariedad del tirano. Y así como el anciano Jicoténcal concluye ante los misterios de la fe que en la «religión todo es violencia y sumisión» (Tomo II, pág. 51), Diego de Ordaz se pregunta por qué no se debe examinar la conducta de los mandatarios, por que hay que obedecerlos ciegamente, cuando fray Bartolomé le dice que quien tiene autoridad y obra de un determinado modo «tendrá sus motivos para ello, que no nos toca a nosotros examinar» (Tomo I, pág. 146).

La novela, por lo tanto, señala que la religión no es un principio esencial para la constitución del estado moderno. Al contrario, sugiere su naturaleza antagónica. Sin embargo, aunque la confianza religiosa en la vida inmortal haya perdido su influencia sobre lo se- cular, todavía no existe una indiferencia nueva hacia la cuestión de la muerte. De ahí que se mantenga el mito conclusivo de recompensas y castigos en el más allá como medio de coacción sobre las conciencias, tal como lo mantuvieron los padres fundadores de América y los hombres de la revolución francesa. De este modo, el mito del infierno, elaborado por Platón e introducido muy temprano por la Iglesia en el cuerpo de sus dogmas (en torno al siglo V), volvía a desempeñar la función política y no religiosa que tuvo en su origen. El autor anónimo admite incluso la validez del cristianismo como «reglas de moral» naturales, esto es, comunes a todos los hombres.

Lo cierto es que lejos de ser la esencia de todas las cosas, el vínculo que unía a todos los hombres por encima de sus diferencias, la religión en Jicoténcal queda empobrecida hasta amenaza de control y manual de buenas costumbres, una apariencia de religión. No es la única apariencia.

Dice Marx que los hombres hacen su propia historia, pero no la hacen bajo las circunstancias elegidas por ellos mismos, sino bajo aquellas circunstancias con que se encuentran realmente ${ }^{21}$. Entre éstas, los libertadores se encontraron con el legado que el siglo XVIII dejó del «salvaje». Naturalistas, filósofos, literatos... todos se ocuparon de él. El «salvaje» era objeto de discurso porque resultaba apto para encarnar la idea de una naturaleza universal. Cuando se hablaba de él era únicamente para hablar de la naturaleza, de su sabiduría, de la razón natural opuesta al artificio y a la convención; pero también de la naturaleza cruel y de la ineficacia y debilidad del derecho natural en relación al derecho positivo. Era la naturaleza la que permitía pensar en el «salvaje» como el hombre natural y el primer atributo de este «salvaje» según apuntaba la $E n$ ciclopedia de Diderot y D'Alembert era la libertad. Por otro lado, este «salvaje» como hombre natural, desde que Colón escribió a Santángel que era «la mejor gente» y tenía «una habla la más dulce del mundo y siempre con risa», era el indio americano. ¿Qué escándalo -debió pensar el autor de Jicoténcal desde el interior de esta tradición- que la América permanezca sometida!

Los cambios siempre dan miedo a los hombres y cuando éstos van a crear algo nunca visto, en estas épocas de crisis revolucionaria, su miedo es tal que «conjuran temerosos 
en su auxilio los espíritus del pasado, toman prestados sus nombres, sus consignas de guerra, su ropaje para con este disfraz de vejez venerable y este lenguaje prestado, representar la nueva escena de la historia universal» $»^{22}$. Dice Marx que los revolucionarios franceses tomaron el disfraz de la antigua Roma ${ }^{23}$. En la gran tarea legislativa que les tocaba acometer ningún ejemplo más adecuado que Roma podía encontrarse. El autor de Jicoténcal optó por el disfraz republicano que podía ofrecer Tlascala, con lo cual las nuevas repúblicas no solo eran las herederas de aquellas naciones indígenas que ahora vengarían de su sometimiento a la corona de España, sino que además restaurában una tradición de libertad, esa libertad que encarnaba América, confiscada por el tirano. La autoctonía, sin embargo, no podía ser sino limitada y así Jicoténcal vestía también de romano: «En efecto, este generoso y valiente americano proyectaba una venganza noble $y$ digna de un alma republicana; y cual otro Bruto, juró la muerte del tirano" (Tomo II, pág. 122).

En sus revoluciones, franceses e hispanoamericanos resucitaron a los muertos para glorificar las nuevas luchas, para alentar el espíritu de la revolución; pero en esos disfraces encontraron también las ilusiones que necesitaba para ocultarse a sí mismos el contenido burguesamente limitado de sus luchas. Concluidas éstas, la legislación mantuvo el baile de disfraces declarando como derechos del hombre, esos derechos naturales e imprescriptibles, diferentes a los del ciudadano, lo que no eran sino los derechos del miembro de la sociedad burguesa, es decir, del hombre aislado del hombre y de la comunidad.
Karl Marx, El dieciocho brumario de Luis Bonaparte, en El Manifiesto comunista $y$ ofros ensayos, op. cit., págs. 103-210, pág. 107.

23

Ibidem, págs. 107-108.

24

Vid. Karl Marx, «Los derechos del hombre y los derechos del ciudadano», en Antología. 